\title{
Against Antibacterial and Antifungal Activity of Jojoba Wax Liquid (Simmondsia chinensis)
}

\author{
Ahmed Al-Ghamdi ${ }^{*}$, Thanaa Elkholy ${ }^{2}$, Shahd Abuhelal ${ }^{3}$, Hatim Al-Abbadi ${ }^{4}$, Dina Qahwaji ${ }^{5}$, \\ Nahlaa Khalefah ${ }^{5}$, Hanaan Sobhy, ${ }^{6}$, Mohammad Abu-Hilal ${ }^{7}$
}

\begin{abstract}
Ahmed Al-Ghamdi ${ }^{*}$, Thanaa Elkholy², Shahd Abuhelal $^{3}$, Hatim Al-Abbadi ${ }^{4}$, Dina Qahwaji ${ }^{5}$, Nahlaa Khalefah ${ }^{5}$, Hanaan Sobhy ${ }^{6}$, Mohammad Abu-Hilal ${ }^{7}$
\end{abstract}

'Department of Medical Laboratory Technology, Faculty of Applied Medical Sciences, King Abdulaziz University, Jeddah, SAUDI ARABIA. ${ }^{2}$ Al-Azhar University, Al Mokhaym Al Daem, Cairo, Cairo Governorate, EGYPT.

${ }^{3}$ Institute of Pharmaceutical Science, Faculty of Life Sciences and Medicine, King's College London, Franklin-Wilkins building, 150 Stamford Street, London SE1 8NH, UNITED KINGDOM.

${ }^{4}$ Consultant General Laparoscopic Surgeon, King Abdulaziz University, University Hospital, Director of

Experimental Surgery Unit, KFMRC*, Jeddah, SAUDI ARABIA.

${ }^{5}$ Departments of Clinical Nutrition, Faculty of Applied Medical Sciences, King Abdul-Aziz University, Jeddah, SAUDI ARABIA.

${ }^{6} \mathrm{Head}$ of Pharmacology Unit,

-Biochemical, and Toxicology and Food Deficiency.

${ }^{7}$ Consultant Hepatobiliary and Pancreatic Surgery, University Hospital, Southampton University, UNITED KINGDOM.

\section{Correspondence}

\section{Ahmed Al-Ghamdi}

King Fahd Medical Research Centre, King Abdulaziz University-Jeddah, Saudi Arabia, P.O.Box 80200, Jeddah 21589, SAUDI ARABIA.

Phone no : 7714-653155-653155

E-mail: aalghamdi@kau.edu.sa.

\section{History}

- Submission Date: $x x-x x-x x x x$;

- Review completed: $x x-x x-x x x x$;

- Accepted Date: $x x-x x-x x x x$

DOI : 10.5530/pj.2019.11.31

Article Available online

http://www.phcogj.com/v11/i1

Copyright

(C) 2019 Phcog.Net. This is an openaccess article distributed under the terms of the Creative Commons Attribution 4.0 International license.

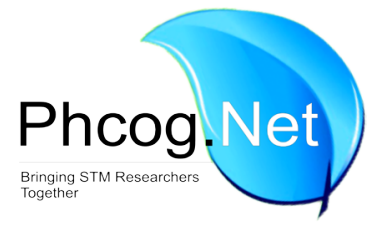

\begin{abstract}
Introduction: Plants are a rich source of bioactive compounds. Simmondsia chinensis, also known as Jojoba, is the sole member the Simmondsiaceae's family and has been known traditionally for many medical uses. Objectives: Herein we evaluate the value of crude jojoba oil (J.O) as an antimicrobial agent in vitro. Methods: J.O was tested for potential antimicrobial activity against Bacillus subtilis, Staphylococcus aureus, Proteus vulgaris, P. mirabilis, Salmonella typhimurium, Escherichia coli, Pseudomonas aeruginosa, Candida albicans and Asperigillus flavus. Results: Our results did not show any effect on fungi or yeast. However, a significant antibacterial activity was observed against $B$. subtilis, $S$. aureus, $P$. vulgaris, $P$. mirabilis. A high activity was observed for J.O at Minimum inhibitory concentration (MIC) level of $12.5 \mathrm{mg} / \mathrm{ml}$. Interestingly, S. typhimurium, E. coli and PS. aeruginosa were found to be highly resistant. Conclusion: Our findings suggest that J.O may have a medicinal potential as natural antibacterial agent.
\end{abstract}

Key words: Jojoba oil, Antibacterial, Antimicrobial activity, Simmondsia chinesisis, Minimum inhibitory concentration (MIC).

\section{INTRODUCTION}

There are thousands of species of medicinal plants used globally for the cure of different infections. ${ }^{1,2}$ For example previous studies proved that the extracts of Casuarina equisetifolia Forest., Euphorbia hirta L. and Euphorbia tirucalli $L$. have antibacterial activities. ${ }^{3}$ These plants, and others, are used as antimicrobial agents and, extensive work has been carried out to determine their scientific basis. ${ }^{4,5,6,7,8}$ Other plants including Zingiber officinale, have been used as herbal drugs to treat inflammation by local inhabitants from ancient times until today. ${ }^{9}$ The medicinal value of the plants lies in some chemical substances that can either produce a definite physiological action on the human body or even act as antibiotics by attacking bacterial cells. ${ }^{10,11,12}$

Simmondsia chinesisis is a plant from the family (Simmondsiaceae) known as Jojoba. It is native of southern Arizona, USA. The seeds of Jojoba plant produce more than $45 \% \mathrm{w} / \mathrm{w}$ of colourless, odourless oily material which was discovered by the native Americans who recognised its important medicinal values. ${ }^{13,14}$ Due to its high economic value, Jojoba is being cultivated in different parts of the world including the Egyptian dessert and Saudi Arabia. ${ }^{15,16}$ Many studies have focused on understanding the antibacterial features of Jojoba. ${ }^{17,18,19}$

Jojoba oil has a unique chemical structure; it is composed of oil sterols, and different toccopherols. ${ }^{13,20,21}$

Jojoba seeds also contain a considerable amount of tannins. ${ }^{22,23,24}$ It has straight chains of C-20 and C-22 acids and alcohol monoesters, in addition to some triglycerides and stanols. ${ }^{13,25}$ Flavonoids are believed to be responsible for the antibacterial activity of Jojoba oil. ${ }^{26,27}$ Since it also works as a carrier substance for oxidation sensitive materials such as Vitamin A; the crude J.O. was used as a cosmetic and skin care material. ${ }^{26,27,28,29}$ Moreover, Jojoba wax has been shown to be the best liquid wax to stabilize penicillin products. ${ }^{28}$

The aim of the present work is to study the antimicrobial activity of J.O at different concentrations against different microorganisms.

\section{Experimental \\ MATERIALS}

Tested oil Crude J.O. was obtained from Egyptian Natural Oil Company. It was prepared from Jojoba nuts (Simmondsia Chinensis).

Microorganisms The microorganisms used in this study were isolated locally and consisted of bacterial and fungal strains. These strains (Bacillus subtilis, Staphylococcus aureus, Proteus vulgaris, P. mirabilis, Salmonella typhimurium, Escherichia coli, Pseudomonas aeruginosa, Candida albicans and Asperigillus flavus) were obtained from the Microbiological Department of Animal Health Research Institute 
Table 1: Antimicrobial activity of jojoba oil on different tested microorganisms tested using agar gel growth inhibition test.

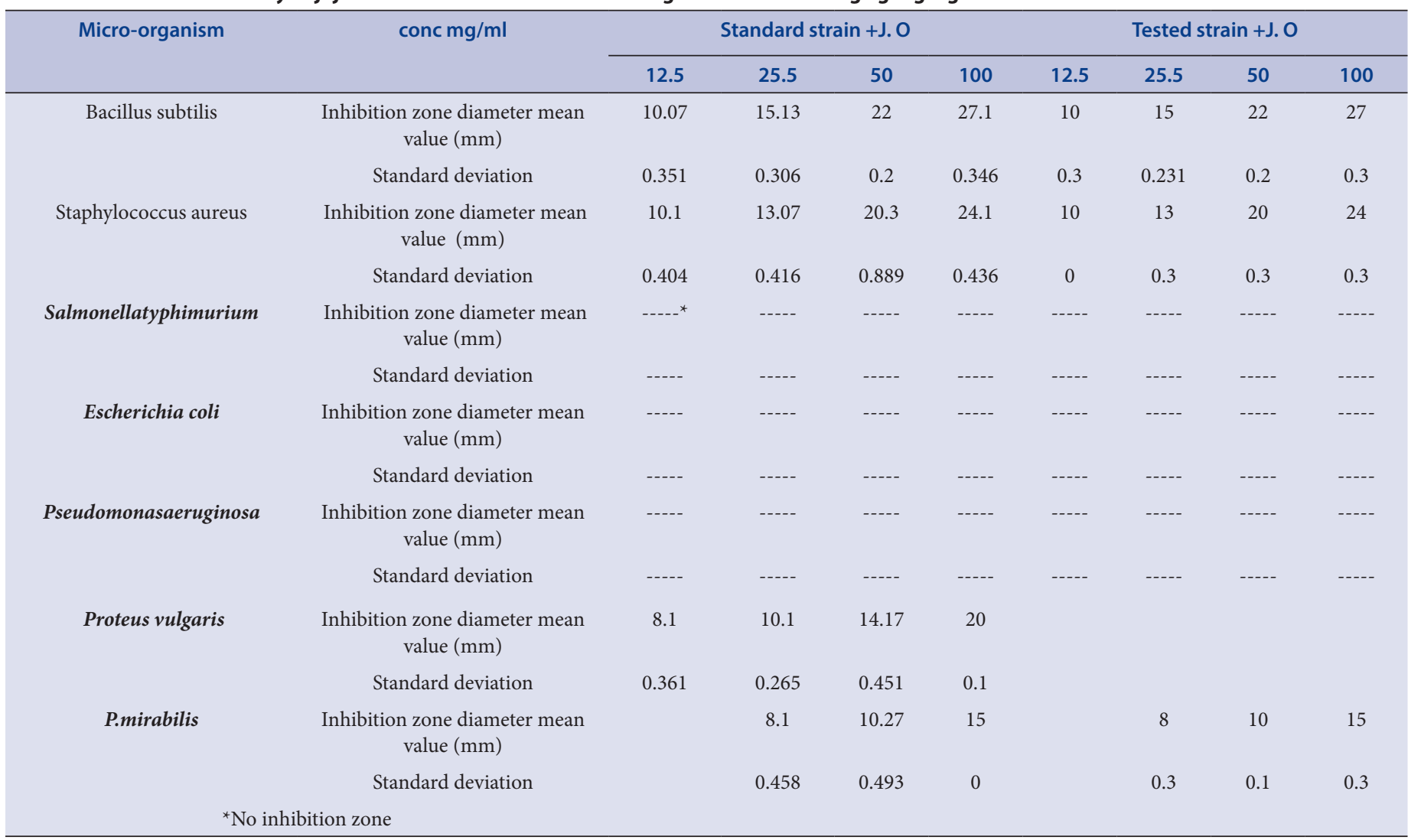

Table 2: antimicrobial activity of jojoba oil on different tested fungi.

\begin{tabular}{cccccc}
\hline Strain of Fungi & control & \multicolumn{4}{c}{ Jojoba concentration } \\
\hline & 0.0 & 12.5 & 25 & 50 & 100 \\
Candida albicans & $------^{*}$ & --- & --- & -- & -- \\
Asperigillus flavus & -------- & --- & --- & -- & -- \\
\hline
\end{tabular}

* No inhibition zones.

(AHRI), Cairo, Egypt. All the used microorganisms were prepared and tested according to Kone man and Cruickshank. ${ }^{30,31}$

\section{METHODS}

Microorganisms maintenance Bacterial strains were grown and maintained on Nutrient Agar slants and on Sabouraud Glucose Agar slants, and then stored at $4^{\circ} \mathrm{C}$. Both bacteria and Candida albicans were sub-cultured in fresh media at regular intervals while, Aspergillus flavus was cultured on Potato Dextrose Agar (PDA) and sub-cultured at regular intervals until used for the antimicrobial tests. All bacterial strains were compared with a reference (standard strains) which were obtained from bacterial strain bank.

All tested strains were prepared and tested against J.O. for estimating the Minimum inhibitory concentration (MIC). Each isolate was tested three times to determine the mean reading. At the same time, the reference isolates, were tested against the same extract with the same concentrations and the same environmental conditions to determine the MIC mean reading (each isolate was tested 3 times)

\section{Antibacterial Activity}

The antibacterial activity of J.O was determined using the Agar Diffusion Method with $1 \mathrm{ml}$ of inoculum, containing 105 bacterial cells (Bookye -Yiadam, 1979). Fresh broth cultured of test organisms (standardized
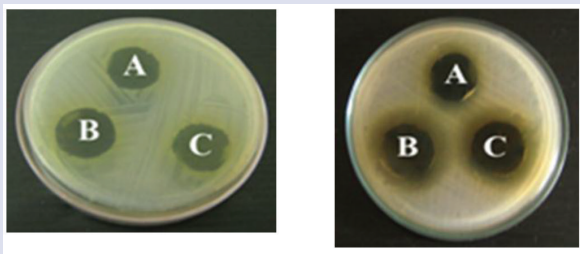

A. Proteus vulgaris

B. Bacillus subtitles
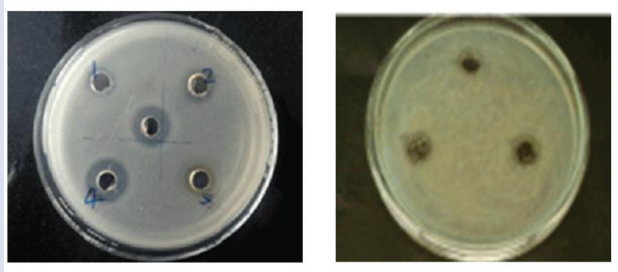

C. P. mirabili

D. Escherichia coli
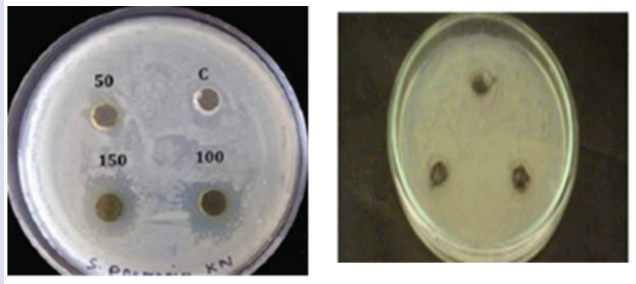

E. Staph.aureus,

F. Salmonella typhimurium

Figure 1: antibacterial activity against different bacterial strains. 
inoculate) was swabbed onto sterile Mueller Hinton Agar in petri dishes. A sterile stainless-steel corn borer $(12 \mathrm{~mm})$ was used to make the wells on the plates. The holes were filled with crude J.O. in different concentrations in water $(12.5,25,50$ and $100 \mathrm{mg} / \mathrm{ml})$. For control experiments, holes were filled with sterile distilled water. Incubated petri dishes were left for an $\mathrm{h}$ at room temperature for the J.O. to diffuse before the growth of organisms commenced and then incubated at $37^{\circ} \mathrm{C}$ for $24 \mathrm{~h}$. The microbial growth was determined by measuring the diameter of the zone of inhibition $(\mathrm{mm})$. The experiments were done three times and mean values have been presented in our results.

\section{Antifungal Activity}

Pour Plate Method was used for the assay of J.O effect against Asperigillus flavus (4x105 fungal spores / plates). J.O was introduced into the test tubes containing sterile Potato Dextrose Agar (PDA). Different J.O Concentrations $(12.5,25,50$ and $100 \mathrm{mg} / \mathrm{ml})$ were used. These were dispensed on petri dishes and could set. Each plate was bored with sterile corn borer of $12 \mathrm{~mm}$ in diameter. Control experiments were also set up performed without the presence of J.O. Plates were incubated at $30^{\circ} \mathrm{C}$ for 3 days.

\section{Determination of Minimum Inhibitory Concentration (MIC)}

After determining the inhibition, the MIC of tested samples at different concentrations was measured against the tested organisms. Agar Diffusion Method described for antibacterial test was also used in determining antifungal action of J.O against Candida albicans.

\section{RESULT}

\section{Antibacterial Activity}

The antibacterial activity tests of J.O was tested against different bacterial strains. Standard bacterial strains obtained from bacterial strain bank were used as a reference. All results are shown below Table 1. Growth inhibition is indicated by clear zones. As shown, the J.O was effective against some of the common bacteria (B. subtilis, S. aureus, P. vulgaris, P. mirabilis).

\section{Antifungal Activity}

The antifungal activity tests of J.O results are shown below Table 2 .

Determination of Minimum Inhibitory Concentration (MIC)

MIC results are shown in both Table 1 and Table 2. Results for Agar Diffusion Method are shown in Figure 1(A-F).

\section{DISCUSSION}

The results of testing the antibacterial activity of J.O on nine different microorganisms demonstrated the presence of antimicrobial activity in J.O. These results are in line with previous reports. ${ }^{32,33,34}$ However, the results disagree with Hani et al who reported that Jordanian J.O. did not exhibit any antimicrobial activity although it exhibited strong antioxidant activity. This can be related to the lower doses used in their experiments. ${ }^{35}$ In addition, the Jojoba used in our study and that used by Hani et al come from two different sources; whether the content and the efficacy of the plant differs when grown in different countries and under different climates is an interesting matter of discussion. In fact, El-Mallah et al have reported on the presence of unique properties and differences in the oil components of the Jojoba seeds cultivated in Egypt in comparison with Jojoba seeds cultivated in Arizona, ${ }^{21}$ however further assessment and investigations on this can be the subject of future studies. There was no significant difference in the results observed for our teste bacterial strains and the reference strains, this indicates that the bacteria which was used for the tests had the same expected sensitivity of the standard bacterial strains. Our data showed that the control samples were not sensitive towards any of the microbial species used. Moreover, S. typhimurium, E. coli, Ps. aeruginosa were not sensitive (with no zone of inhibition) to all concentrations of J.O. Similarly, C. albicans and A. flavus did not show any sensitivity to J.O.

P. mirabilis was the least sensitive bacterium with $15 \mathrm{~mm}$ and $10 \mathrm{~mm}$ zones of inhibition at concentrations of 100 and $50 \mathrm{mg} / \mathrm{ml}$ respectively. On the other hand, B. subtilis and S. aureus were the most sensitive with $10 \mathrm{~mm}$ at concentration of $12.5 \mathrm{mg} / \mathrm{ml}$ and reached to $27 \mathrm{~mm}$ at concentration of $100 \mathrm{mg} / \mathrm{ml}$.

Those results reinforce the previous findings on the presence of antimicrobial activities in Jojoba. ${ }^{2,36}$ We do agree that the antibacterial constituents in some plants may not be well effective if the concentrations are inadequate. , $35^{2}$

\section{CONCLUSION}

Our findings suggest that J.O exhibits potent antimicrobial properties. Antimicrobial tests showed that J.O exhibited a broad spectrum of activity by inhibiting the growth of some of the investigated bacteria. J.O appears to be a promising source of bioactive compounds with antimicrobial properties.

\section{ACKNOWLEDGMENT}

The authors acknowledge with thanks Deanship of Scientific Research (DSR) technical and financial support.

\section{CONFLICT OF INTEREST}

The authors certify that they have NO affiliations with or involvement in any organization or entity with any financial or non-financial interest in the subject matter or materials discussed in this manuscript.

\section{ABBREVIATIONS}

JO: jojoba oil

MIC: Minimum inhibitory concentration

PDA: Potato Dextrose Agar

\section{REFERENCES}

1. Murugan T. Antimicrobial Activity of Leaves and Latex Extract of the Herbal plant Calotropis gigantean. International Journal of Biology, Pharmacy and Allied Sciences. 2012;1(3):261-70.

2. Abd-Aziz Z Jojoba leaf extracts: potential as antimicrobial and antinematode agents. in Proc. Ninth Int. Conf. on jojoba and its uses. The third Int. Con. New. Ind. crops and prod., Catamarca, Argentina. 1994.

3. Parekh J, Jadeja D, Sumitra C. Efficacy of aqueous and methanol extracts of some medicinal plants for potential antibacterial activity. Turkish Journal of Biology. 2006;29(4):203-10.

4. Srinivasan D. Antimicrobial activity of certain Indian medicinal plants used in folkloric medicine. Journal of Ethnopharmacology. 2001;74(3):217-20.

5. Rios J, Recio M. Medicinal plants and antimicrobial activity. Journal of ethnopharmacology. 2005;100(1):80-4.

6. Elgayyar M. Antimicrobial activity of essential oils from plants against selected pathogenic and saprophytic microorganisms. Journal of Food Protection $\circledast$. 2001;64(7):1019-24.

7. Kabara JJ. Fatty acids and derivatives of antimicrobial agents. 1977. Google Patents.

8. Encarnacion DR, Virgen M, Ochoa N. Antimicrobial activity of medicinal plants from Baja California Sur (Mexico). Pharmaceutical biology. 1998;36(1):33-43.

9. Al-Daihan S. Antibacterial activity and phytochemical screening of some medicinal plants commonly used in Saudi Arabia against selected pathogenic microorganisms. Journal of King Saud University Science. 2013;25(2):115-20.

10. Abou-Arab EA, Abou-Salem FM. Evaluation of bioactive compounds of Stevia rebaudiana leaves and callus. Mansoura University Journal of Food and Dairy Sciences. 2010;4(10):627-34

11. Desbois AP, Smith VJ. Antibacterial free fatty acids. Applied Microbiology and Biotechnology. 2010;85(6):1629-42.

12. Pohl CH, Kock JL, Thibane VS. Antifungal free fatty acids: a review. Science 
against microbial pathogens: current research and technological advances. 2011;3:61-71.

13. Tada AJZ, Sugimoto N, Sato K, Zmayaki T, Tanamoto K. Analysis of the constituents in jojoba wax used as a food additive by LC/MS/MS. J Food Hygienic Society of Japan. 2005;46(5):198-204

14. McKelvie L, Bills J, Peat A. Jojoba, Blue Mallee and Broombush: Market Assessment and Outlook. ABARE Research Report. 94.9.1994. Australia, Canberra. Australian Bureau of Agricultural and Resource Economics (ABARE).

15. Aydinlatmasi EE. Structural elucidation of Jojoba plant (Simmondsia Chinensis) oil from Saudi Arabia. J Fac Pharm. 2002;31(4):223-9.

16. Ashour ML. Simmondsia Chinensis (Jojoba): A comprehensive pharmacognostic study. Journal of Pharmacognosy and Phytochemistry. 2013;2(2).

17. De Prijck K, Peeters E, Nelis H. Comparison of solid-phase cytometry and the plate count method for the evaluation of the survival of bacteria in pharmaceutical oils. Letters in applied microbiology. 2008;47(6):571-3.

18. Pawar B, Papdiwal P. Antibacterial activity of some leaf extract against Xanthomonas campestris pv. Mangiferaeindicae. International Journal of Plant Protection. 2010;3(1):104-6.

19. Salem S. Chemical studies on Jojoba oil. 2003.

20. Green M. Simple conjugated polymer nanoparticles as biological labels. 2009;465(2109):2751-9.

21. El-Mallah MH, El-Shami SM. Investigation of liquid wax components of Egyptian jojoba seeds. Journal of oleo science. 2009;58(11):543-8.

22. Omotayo A. Antibacterial activity of some antimalarial plants. Proceeding of Nigerian Society for Microbiology. 1998;39:69-72.

23. Wiseman MO, Price RL. Characterization of protein concentrates of jojoba (Simondsia chinensis) meal. Cereal Chemistry. 1987;64:91-3.

24. Wiseman $\mathrm{MO}$, Price RL. Functional properties of protein concentrates from pressed jojoba meal. Cereal Chemistry. 1987;64:94-7.

25. Léon F. Isolation and identification of molecular species of phosphatidylcholine and lysophosphatidylcholine from jojoba seed meal (Simmondsia Chinensis). Journal of agricultural and food chemistry. 2004;52(5):1207-11.

26. Alexander P. SCS looks at better cosmetic formulation. 1985, miller freeman technical $1^{\text {td }} 30$ Calderwood st, London, England se18 $6 \mathrm{qh}$.

27. Gunstone FD. Jojoba oil. Endeavour. 1990;14(1):40-3.

28. Daugherty $\mathrm{PH}$, Sineath $\mathrm{H}$, WastlerT. Industrial raw materials of plant origin. IV. A survey of Simmondsia Chinensis (Jojoba). Economic Botany. 1958;12(3):296-304.

29. Aburjai T, Natsheh FM. Plants used in cosmetics. Phyto therapy Research. 2003;17(9):987-1000.

30. Koneman EW, Allen SD, Janda WM. Introduction to diagnostic microbiology. 1996. USA: Lippincott d Comp.

31. Cruickshank R, Duguid JP. Medical microbiology 1975;2(ed 12). Churchil Livingston, London: th Ed.

32. Guirguis OW, Elkader MFA, Nasrat AA. Enhancing antimicrobial activity for chitosan by adding Jojoba liquid wax. Materials Letters. 2013;93:353-5.

33. Abu-Salem FM, Ibrahim HM. Antimicrobial Activity and Phytochemicals Screening of Jojoba (Simmondsia Chinensis) Root Extracts and Latex. World Academy of Science, Engineering and Technology. International Journal of Biological, Biomolecular, Agricultural, Food and Biotechnological Engineering. 2014;8(5):517-22.

34. Aiyelaagbe $O$. In vitro antimicrobial activity and phytochemical analysis of Jatropha curcas roots. Inter J. Pharmacology. 2007;3(1):106-10.

35. Hani AQ. Antioxidant and antimicrobial activities of Jordanian Simmondsia Chinensis (link) CK Schneid. European Scientific Journal. 2014;10(27).

36. Strainer RY. General Microbiology. 5 ed. 1986, London: The MacMillan Press Ltd.

\section{GRAPHICAL ABSTRACT}

\section{ABOUT AUTHORS}

Cite this article: Al-Ghamdi AK, Elkholy TA, Abuhelal S, Al-Abbadi H, Qahwaji D, Khalefah N, Sobhy H, Abu-Hilal M. Phytochemical Investigation and In-vitro Anthelmintic Activity of the Leaves of Gynura lycopersicifolia Linn. Pharmacog J. 2019;11(1):191-4.

\section{SUMMARY} maceutical field for a while. Many studies about the use of Jojoba oil antibacterial and antifungal activities has been performed with different findings. In this study, we evaluate the value of crude jojoba oil (J.O) as an antimicrobial agent in vitro. J.O was tested for potential antimicrobial activity against Bacillus subtilis, Staphylococcus aureus, Proteus vulgaris, P. mirabilis, Salmonella typhimurium, Escherichia coli, Pseudomonas aeruginosa, Candida albicans and Asperigillus flavus. Our results did not show any effect on fungi or yeast. However, a significant antibacterial activity was observed against $B$. subtilis, $S$. aureus, P. vulgaris, P. mirabilis. A high activity was observed for J.O at Minimum inhibitory concentration (MIC) level of $12.5 \mathrm{mg} / \mathrm{ml}$. Interestingly, S. typhimurium, $E$. coli and Ps. aeruginosa were found to be highly resistant. These results, suggest that J.O may have a medicinal potential as natural antibacterial agent.
- Jojoba oil has been attracting researcher's attention in the medical and phar

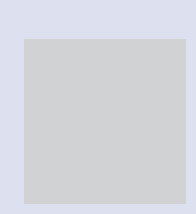

